\title{
miR-328-5p inhibits MDA-MB-231 breast cancer cell proliferation by targeting RAGE
}

\author{
TINGTING LUO ${ }^{1}$, YUEQIONG YAN ${ }^{1}$, QIUXIA HE ${ }^{1}$, XIAOQIAN MA $^{2}$ and WEI WANG ${ }^{2}$ \\ Departments of ${ }^{1}$ Ultrasonography and ${ }^{2}$ Radiology, The Third Xiangya Hospital, \\ Central South University, Changsha, Hunan 410011, P.R. China \\ Received October 16, 2017; Accepted March 21, 2018
}

DOI: $10.3892 /$ or.2018.6353

\begin{abstract}
MicroRNAs (miRNAs) are a class of short noncoding RNAs that play an important role in gene regulation and are critically involved in the pathogenesis and progression of human cancer. miR-328-5p has been reported to potentially act as a sensitising agent in breast cancer, but its other cellular functions and mechanisms remain unknown. The primary aim of the present study was to discover additional cellular functions and mechanisms of miR-328-5p in the breast cancer cell line MDA-MB-231. In the present study, miRNA microarray was used to find altered miRNAs. MTT and colony formation were used to test cell proliferation. Flow cytometry and western blotting were used to explore potential mechanisms of miR-328-5p regulating cell proliferation. A luciferase reporter assay was used to confirm target binding. miR-328-5p was revealed to be significantly upregulated after knockdown of the receptor for advanced glycosylation end products (RAGE). We also confirmed that miR-328-5p was frequently decreased in breast cancer tissues. Moreover, miR-328-5p mimics inhibited MDA-MB-231 proliferation, drug resistance and cell cycle progression. We confirmed that RAGE was a direct target of miR-328-5p. Functions of miR-328-5p in MDA-MB-231 cells were elucidated by targeting RAGE. In conclusion, these results revealed that miR-328-5p may be considered as a tumour-suppressor factor, and promoting miR-328-5p expression could be a novel therapeutic strategy for breast cancer.
\end{abstract}

Correspondence to: Professor Wei Wang, Department of Radiology, The Third Xiangya Hospital, Central South University, 138 Tongzipo Road, Changsha, Hunan 410011, P.R. China

E-mail: cjr.wangwei@vip.163.com

Abbreviations: miRNAs, microRNAs; RAGE, receptor for advanced glycosylation end-product specific receptor

Key words: miR-328-5p, RAGE, breast cancer, proliferation, microarray

\section{Introduction}

Breast cancer is considered the most common malignancy and the main leading cause of cancer-related deaths in women $(1,2)$. The pathogenesis and mechanisms of breast cancer remain unclear. Therefore, further studies at the molecular level are necessary. Various related molecular markers [ER, PR and HER-2 $(3,4)]$ are used in clinical practice to guide the diagnosis, treatment and prognosis of breast cancer, however they are only used to diagnose a small group type with poor prognosis of breast cancer. Therefore, finding a tumour marker of breast cancer that has high sensitivity and specificity, can be used for early diagnosis, individualised treatment, monitoring the curative effect and individual prognosis is highly important.

MicroRNAs (miRNAs) are highly conserved non-coding small RNAs, 18-25 nucleotides in length, that widely exist in plants and animals and can regulate cell differentiation, proliferation, metabolism and apoptosis by inhibiting transcription of protein coding genes or inducing their mRNA degradation (5). miRNAs possess advantages such as non-invasiveness, stability, high sensitivity and free from the influence of blood cell components; hence, they have the characteristics of ideal tumour markers (6). Therefore, further study of miRNAs is expected to improve the diagnosis and treatment of breast cancer.

The receptor for advanced glycosylation end products (RAGE) is a type of membrane protein belonging to the immunoglobulin superfamily. Our previous research revealed that RAGE is an oncogene in breast cancer (7). Stoetzer et al considered RAGE as a circulating immunogenic cell death biomarker (8). Therefore, targeting RAGE is considered a novel strategy for clinical intervention in breast cancer. To investigate the mechanism of RAGE and discover important miRNAs for breast cancer, we screened miRNAs microarray after interfering with the expression of RAGE in breast cancer cells.

In the present study, we found that miR-328-5p was significantly upregulated after knockdown of RAGE. We investigated the anti-oncogenic role of miR-328-5p and its correlation to proliferation in breast cancer cells. We confirmed that there was direct binding between miR-328-5p and RAGE. Furthermore, the inhibitory functions of miR-328-5p in breast cancer cells were positively correlated with RAGE. 


\section{Materials and methods}

Cell line and culture. The human breast cancer cell line MDA-MB-231 was purchased from the American Type Culture Collection (ATCC; Manassas, VA, USA). The cells were cultured in RPMI-1640 medium (HyClone, Hudson, NH, USA) supplemented with $10 \%$ fetal bovine serum (FBS) at $37^{\circ} \mathrm{C}$ and $5 \% \mathrm{CO}_{2}$.

Cell transfection. The knockdown of RAGE in MDA-MB-231 cells was performed using siRNA. The sequence targeting RAGE was 5'-CAC TGC AGT CGG AGC TAA TGG-3'. A scrambled oligo siRNA (Santa Cruz Biotechnology, Inc., Dallas, TX, USA) was used as a control at the same concentration. The overexpression of RAGE was accomplished using a pcDNA3.1 vector. The overexpression of miR-328-5p in MDA-MB-231 cells was performed using miR-328-5p mimics, and scramble mimics were used as the control at the same concentration. MDA-MB-231 cells were initially plated in media containing 10\% FBS. After $24 \mathrm{~h}$, the cells were washed once with phosphate-buffered saline (PBS) and transfected with vector/mimics/siRNA or scrambled siRNAs by Nucleofector (Lonza Group, Ltd., Basel, Switzerland) according to the manufacturer's instructions.

miRNA microarray analysis. MDA-MB-231 cells transfected with siRAGE and scrambled siRNAs were subjected to Agilent Human miRNA microarray $(8 \times 60 \mathrm{~K})$ analysis at the Oebitech Co. (Shanghai, China). Total RNA was quantified using NanoDrop ND-2000 (Thermo Fisher Scientific, Inc., Waltham, MA, USA), and the RNA integrity was assessed using Agilent Bioanalyzer 2100 (Agilent Technologies, Inc., Santa Clara, CA, USA). The sample labelling, microarray hybridisation and washing were performed according to the manufacturer's standard protocols. Briefly, total RNA was dephosphorylated, denatured and then labelled with cyanine3-CTP. After purification, the labelled RNAs were hybridised onto the microarray. After washing, the arrays were scanned with the Agilent Scanner G2505C (Agilent Technologies Inc.). Feature Extraction software (version 10.7.1.1; Agilent Technologies, Inc.) was then used to analyse array images to obtain the raw data. GeneSpring software (version 13.1; Agilent Technologies) was employed to complete the basic analysis of the raw data. The threshold set for upregulated and downregulated genes was a fold change of $\geq 2.0$ and a P-value $\leq 0.05$. The target genes of differentially expressed miRNAs were predicted with three databases (TargetScan, microRNA.org and PITA). Gene Ontology (GO) and Kyoto Encyclopaedia of Genes and Genomes (KEGG) analyses were performed to determine the roles of these target genes. Hierarchical clustering was performed to reveal the distinguishable miRNA expression patterns among samples.

RNA extraction and quantitative real-time polymerase chain reaction $(q P C R)$. Total RNA was extracted from cell lines and tissues using TRIzol (Dongshen Biotech, Co., Ltd. Guangzhou, China). RevertAid First Strand cDNA Synthesis Kit (Thermo Fisher Scientific, Inc.) was used for reverse transcription. qPCR was performed using an ABI Prism 7300 Sequence Detection System (Applied Biosystems; Thermo Fisher Scientific, Inc.) with SYBR-Green PCR mixture (Dongshen Biotech, Co., Ltd.). The miRNA and U6 primers were purchased from GeneCopoeia (Guangzhou, China). The RAGE primers were as follows: forward, GGT GCC TAA TGA GAA GGG AGT A and reverse, GAA GCT ACA GGA GAA GGT GGG. The $\beta$-actin primers were as follows: forward, AGG GGC CGG ACT CGT CAT ACT and reverse, GGC GGC ACC ACC ATG TAC CCT. The relative expression level was determined using the $2^{-\Delta \Delta \mathrm{Ct}}$ analysis method, in which $\beta$-actin and U6 were used as internal standards. All reactions were conducted in triplicate, and all experiments were performed in three independent replicates.

Tissue collection. The 13 paired patient tissues (breast cancer and adjacent tissues) were collected during surgical resection at the Third Xiangya Hospital (from May 2015 to September 2017). All patient tissues were confirmed by histopathological evaluation. The study was approved by the Ethical Committee of the Third Xiangya Hospital of Central South University. No patients received preoperative radiotherapy and/or chemotherapy. The collected tissues were immediately stored at $-80^{\circ} \mathrm{C}$ until use.

MTT assay. The cells were collected, and the concentration was adjusted to $5 \times 10^{4}$ cells/well before culture. The cells were cultured in $35-\mathrm{mm}$ dishes at $5 \% \mathrm{CO}_{2}$ and $37^{\circ} \mathrm{C}$ for 24,48 and $72 \mathrm{~h}$. For chemosensitivity detection, the cells were treated with cisplatin (DDP; $0-200 \mu \mathrm{M}$ ) for $48 \mathrm{~h}$. Then, $10 \mu \mathrm{l}$ of MTT was added to the cells and maintained at $5 \% \mathrm{CO}_{2}$ and $37^{\circ} \mathrm{C}$ for another $4 \mathrm{~h}$ before MTT was removed. The optical density value was measured at $570 \mathrm{~nm}$ while the cells were suspended in $150 \mu \mathrm{l}$ of dimethyl sulfoxide (DMSO).

Colony formation assay. The clonogenicity of single cells was detected by colony assay. Cells were collected by adding $0.25 \%$ trypsin and were adjusted to a concentration of 400 cells/petri dish, which was loaded with $2 \mathrm{ml}$ of preheated culture media before culturing with $5 \% \mathrm{CO}_{2}$ at $37^{\circ} \mathrm{C}$ for $2-3$ weeks. Colony formation was terminated when the colonies were visible to the naked eye. Subsequently, the cells were washed twice with PBS, and then $4 \%$ paraformaldehyde was added for $15 \mathrm{~min}$ to fix the cells before staining with Giemsa for $10 \mathrm{~min}$. Then the number of colonies were counted, and the colony formation rate was calculated as follows: Colony formation rate $=$ (number of colonies/inoculation cell number) x $100 \%$.

Cell invasion assay. The invasion ability was determined using a Transwell assay. MDA-MB-321 cells $\left(5 \times 10^{4}\right)$ were plated in Transwell chambers. The chambers were placed in a 24-well plate and incubated for $24 \mathrm{~h}$ at $37^{\circ} \mathrm{C}$. The cells that invaded the membrane were stained using a crystal violet staining solution kit (Beyotime Institute of Biotechnology, Shanghai, China). The stained cells were photographed using an inverted microscope (Motic Inc., Ltd., Causeway Bay, Hong Kong). After capturing the images, the stain from the membrane was eluted in $500 \mu \mathrm{l}$ of DMSO. The eluted staining agent was then shifted into a 96-well plate and the absorbance was assessed using a microplate reader (Thermo Fisher Scientific, Inc.) at $570 \mathrm{~nm}$. 
A

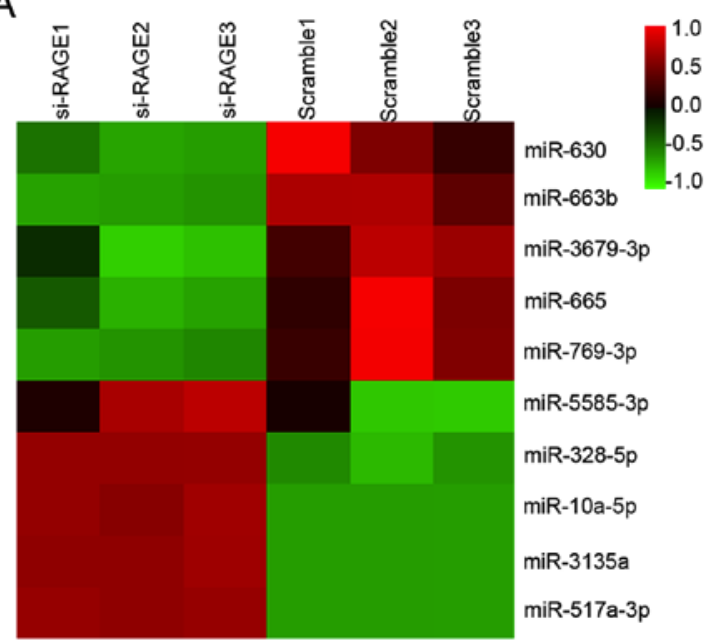

B

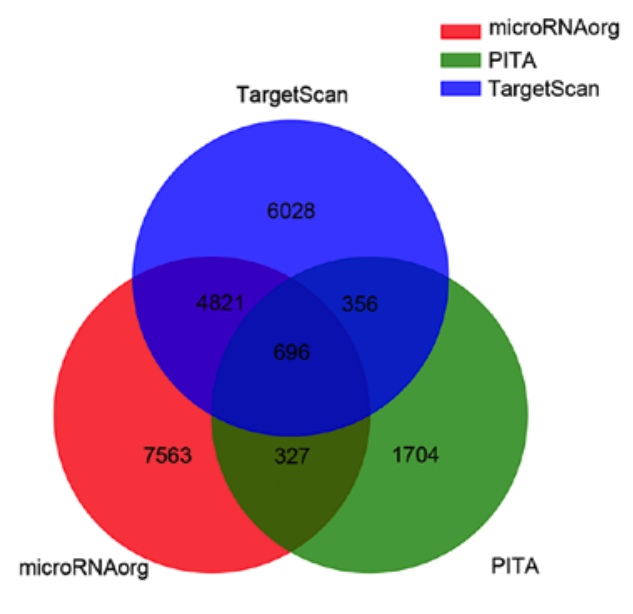

Figure 1. Overview of the miRNA microarray analysis. (A) Hierarchical clustering analysis of differentially expressed miRNAs detected by the miRNA microarray analysis in MDA-MB-231 cells treated with RAGE siRNA for 48 h. (B) Predicted target genes with three databases (TargetScan, microRNA.org and PITA). miRNA, microRNA; RAGE, receptor for advanced glycosylation end-product specific receptor.

Flow cytometric analysis of the cell cycle and cell apoptosis. The cell cycle was assessed via flow cytometry. Cells were trypsinised (Auragene Bioscience Co., Changsha, China) and washed twice with PBS before fixation in $500 \mu 175 \%$ precooled ethanol at $4^{\circ} \mathrm{C}$ overnight. The cells were then washed twice with PBS and incubated in a water bath at $37^{\circ} \mathrm{C}$ for $30 \mathrm{~min}$ with $100 \mu \mathrm{l}$ RNase A (Auragene Bioscience Co.). The cell suspensions were incubated for $30 \mathrm{~min}$ in the dark using propidium iodide (PI) (Beijing Solarbio Science \& Technology Co., Ltd., Beijing, China) or for 15 min using an Annexin V/PI detection kit (Molecular Probes, Inc.; Thermo Fisher Scientific, Inc., Eugene, OR, USA), according to the manufacturer's instructions. Finally, the cell cycle and apoptosis were analysed by FACScanto $^{\mathrm{TM}}$ (BD Biosciences, Franklin Lakes, NJ, USA).

Western blotting. Cells were lysed in cold RIPA buffer, and protein was separated with 10-12\% SDS-PAGE, which was then transferred to NC membranes (Thermo Fisher Scientific, Inc.). The membranes were blocked with 5\% non-fat dried milk (Beijing Yili Fine Chemical Co., Ltd., Beijing, China) in PBS Tween-20 solution $(0.1 \% \mathrm{v} / \mathrm{v})$ for $3 \mathrm{~h}$ at $4^{\circ} \mathrm{C}$. Then, the membranes were incubated with primary antibodies rabbit polyclonal rage (1:1,000; cat. no. ab37647), rabbit polyclonal anti-NF- $\mathrm{B}$ p65 (1:50,000; cat. no. ab32536), rabbit monoclonal anti-cyclin D1 (1:10,000; cat. no. ab134175) and mouse monoclonal anti- $\beta$-actin $(1: 1,000$; cat. no. ab8226; all were from Abcam, Cambridge, MA, USA) overnight at $4^{\circ} \mathrm{C}$, and then with the appropriate secondary antibodies goat antirabbit (1:5,000; cat. no. ab6721) and goat anti-mouse (1:10,000; cat. no. ab6789; both were from Abcam) for $1 \mathrm{~h}$ at room temperature. The immune complexes were detected using ECL Western Blotting kit (Thermo Fisher Scientific, Inc.). The relative protein expression was analysed using Image-Pro Plus software 6.0, using $\beta$-actin as the internal reference.

Luciferase reporter assay. The possibility of miR-328-5p and RAGE target binding was predicted using the online software TargetScan (http://www.targetscan.org/vert_71/). The RAGE mRNA predicted binding site region and mutated site region were cloned into the psi-CHECK2 vector. MDA-MB-231 cells were co-transfected with psi-CHECK2 vectors and miR-122 mimics or scrambled controls. After $48 \mathrm{~h}$, the supernatants were collected and the luciferase activities were assessed using a Dual-Luciferase Reporter Assay system (Promega, Fitchburg, WI, USA).

Statistical analysis. Statistical analysis was performed using GraphPad Prism 6 software (GraphPad Software, Inc., La Jolla, CA, USA) or SPSS 18.0 software (SPSS, Inc., Chicago, IL, USA). All experiments were repeated at least thrice, and the data are shown as the mean \pm standard deviation. An unpaired two-tailed Student's t-test and one-way analysis of variance with Bonferroni post hoc test were used to analyse the data, depending on conditions and group number. The relationship between RAGE and miR-328-5p expression was determined by Pearson correlation analysis. $\mathrm{P}<0.05$ was considered to indicate a statistically significant difference.

\section{Results}

Analysis of differentially expressed miRNAs. In total, 2,550 miRNAs were detected by Agilent Human miRNA microarray. In addition, 10 miRNAs were found to be differentially expressed after knockdown of RAGE, as shown in Fig. 1A. The expression changes and reported functions of the miRNAs are listed in Table I (9-18).

Analysis of the predicted target genes of differentially expressed miRNAs. Target genes of differentially expressed miRNAs were predicted using three databases (TargetScan, microRNA. org and PITA), as shown in Fig. 1B. GO and KEGG analyses were used to determine the roles of these databases with crossed target genes. According to the results shown in Fig. 2, we found that the following targets were principally involved: i) biological processes (transcription from RNA polymerase II promoter, response to mechanical stimulus and regulation of insulin secretion); ii) cellular components (i.e. nucleoplasm, cytoplasm and nuclear chromatin); and iii) molecular functions 
Table I. The fold changes and reported functions of the 10 differently expressed miRNAs.

\begin{tabular}{|c|c|c|c|c|c|}
\hline Name & Fold change & $\begin{array}{l}\text { Control vs. } \\
\text { RAGE siRNA }\end{array}$ & $\begin{array}{l}\text { Reported in } \\
\text { breast cancer }\end{array}$ & Functions in cancers & Refs. \\
\hline $\operatorname{miR}-10 a-5 p$ & 27.93 & Up & $\mathrm{Y}$ & $\begin{array}{l}\text { 1. Reduced in breast cancer and may be a potential } \\
\text { tumor suppressor in breast cancer. } \\
\text { 2. Is deemed as a valuable marker for prognostication } \\
\text { of breast cancer patients. }\end{array}$ & $(9,10)$ \\
\hline miR-3135a & 141.20 & Up & $\mathrm{N}$ & N/A & \\
\hline miR-328-5p & 50.23 & Up & $\mathrm{Y}$ & $\begin{array}{l}\text { Negatively regulates the expression of breast cancer } \\
\text { resistance protein (BCRP/ABCG2) in human } \\
\text { cancer cells. }\end{array}$ & (11) \\
\hline $\operatorname{miR}-517 a-3 p$ & 258.76 & Up & $\mathrm{N}$ & $\begin{array}{l}\text { 1. Induces cell apoptosis in bladder cancer cell lines. } \\
\text { 2. Downregulation of miR-517a promotes proliferation } \\
\text { of hepatocellular carcinoma cells. }\end{array}$ & $(12,13)$ \\
\hline $\operatorname{miR}-5585-3 p$ & 8.82 & Up & $\mathrm{N}$ & N/A & \\
\hline $\operatorname{miR}-630$ & 9.87 & Down & $\mathrm{Y}$ & $\begin{array}{l}\text { Suppresses breast cancer progression, } \\
\text { inhibits cell migration and invasion. }\end{array}$ & (14) \\
\hline $\operatorname{miR}-663 b$ & 7.76 & Down & $\mathrm{Y}$ & $\begin{array}{l}\text { Induces chemotherapy resistance in } \\
\text { human breast cancer cells. }\end{array}$ & $(15)$ \\
\hline $\operatorname{miR}-665$ & 3.05 & Down & $\mathrm{N}$ & $\mathrm{N} / \mathrm{A}$ & \\
\hline $\operatorname{miR}-769-3 p$ & 3.47 & Down & $\mathrm{Y}$ & $\begin{array}{l}\text { 1. Downregulates NDRG1 and enhances apoptosis } \\
\text { in MCF-7 cells during reoxygenation. } \\
\text { 2. Promotes cell proliferation in human melanoma } \\
\text { by suppressing GSK3B expression. }\end{array}$ & $(16,17)$ \\
\hline $\operatorname{miR}-3679-3 p$ & 3.64 & Down & $\mathrm{N}$ & $\begin{array}{l}\text { Promising biomarker of different staging of } \\
\text { lung squamous cell carcinoma. }\end{array}$ & $(18)$ \\
\hline
\end{tabular}

miRNAs, microRNAs; RAGE, receptor for advanced glycosylation end-product specific receptor; N/A, not available; Refs., references. NDRG1, N-myc downstream-regulated gene 1.

(protein and chromatin binding, ionotropic glutamate receptor binding). These genes are mainly involved in the following pathways or conditions: Hippo signalling, alcoholism, Rap1 and various cancer proliferation-related pathways.

Verification of the miRNA microarray results. qPCR was used to assess the microarray results. The results of all 10 differentially expressed miRNAs were the same with the microarray results and had almost similar fold changes, but only slightly lower (Fig. 3).

miR-328-5p is downregulated in breast cancer tissues. Since miR-328-5p has been reported less in breast cancer, it was chosen for further studies. To investigate the role of miR-328-5p in breast cancer, we collected 13 samples of breast cancer tissue and compared these with healthy adjacent tissues. The qPCR results revealed that the expression of miR-328-5p was significantly decreased in breast cancer tissue compared with adjacent tissues (Fig. 4A). To assess the function of miR-328-5p in breast cancer, we used miR-328-5p mimics to construct a miR-328-5p overexpression cell model in MDA-MB-231 cells, with scrambled mimics as a negative control. The representative qPCR assay results, displayed in
Fig. 4B, indicated that our miR-328-5p overexpression model was successfully constructed.

miR-328-5p mimics inhibit cell proliferation, drug resistance and the cell cycle. To elucidate the functions of miR-328-5p in breast cancer, MDA-MB-231 cells were transfected with miR-328-5p and scramble mimics for 24, 48 and $72 \mathrm{~h}$. MTT and colony formation assays revealed that miR-328-5p mimics significantly suppressed cell viability (Fig. 4C and E). However, the Transwell assay revealed that miR-328-5p mimics did not affect cell invasiveness (data not shown). Moreover, chemotherapy resistance against DDP was suppressed in the miR-328-5p mimic group, as previously described by Pan et al (11) (Fig. 4D). To investigate the mechanisms of miR-328-5p inhibition on cellular proliferation and drug resistance, we analysed the effects of miR-328-5p on cell apoptosis and the cell cycle. As shown in Fig. 4F, we found that the cell cycle was significantly arrested in phase G1/S after overexpression of miR-328-5p. However, apoptosis was not influenced (data not shown).

RAGE is a direct target gene of miR-328-5p in MDA-MB-231 cells. The microarray was conducted after knockdown of 
A

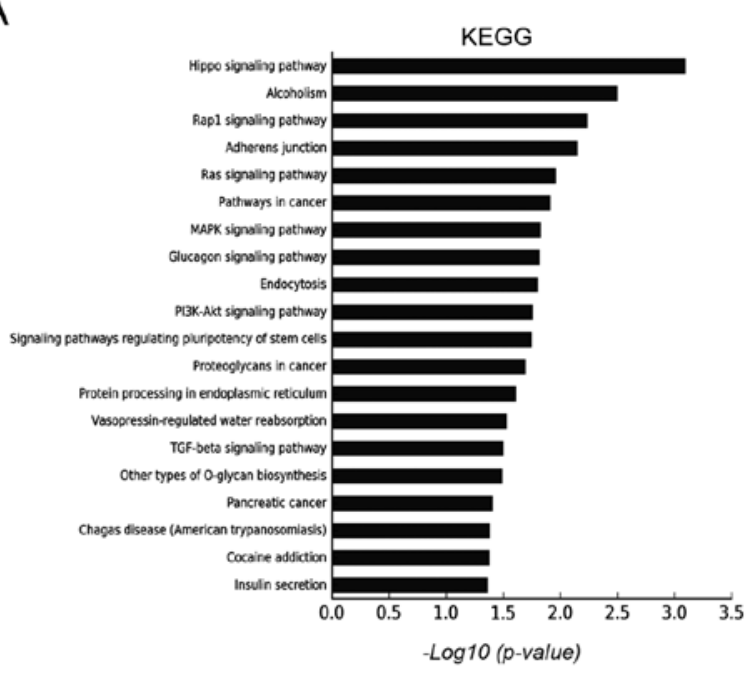

C

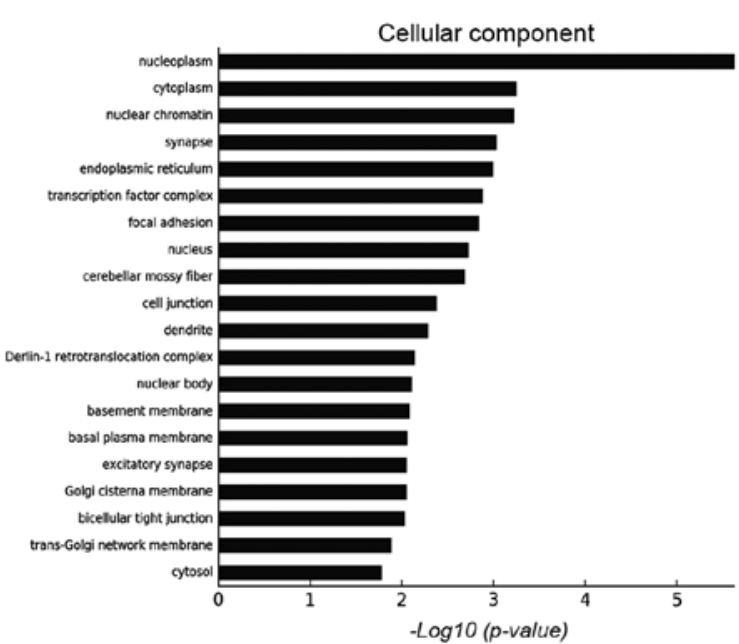

B

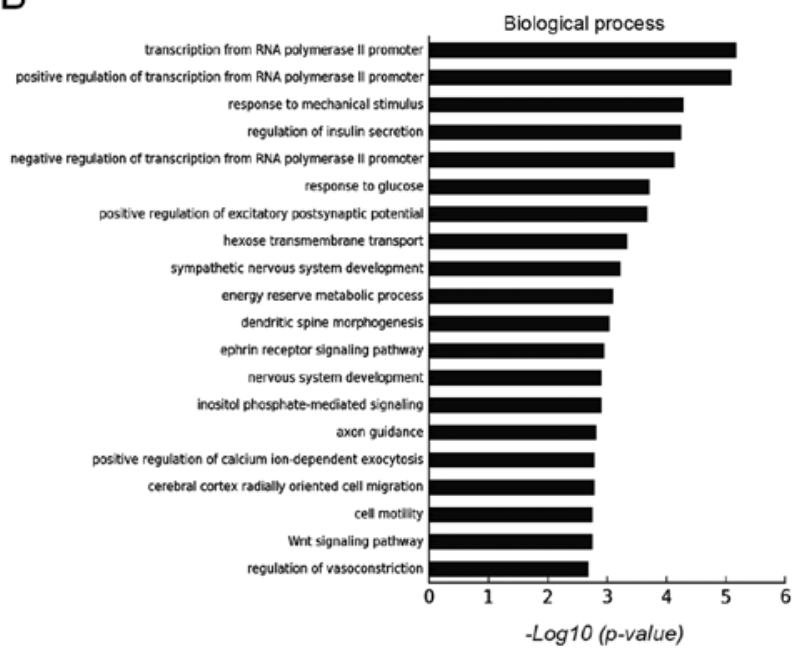

D

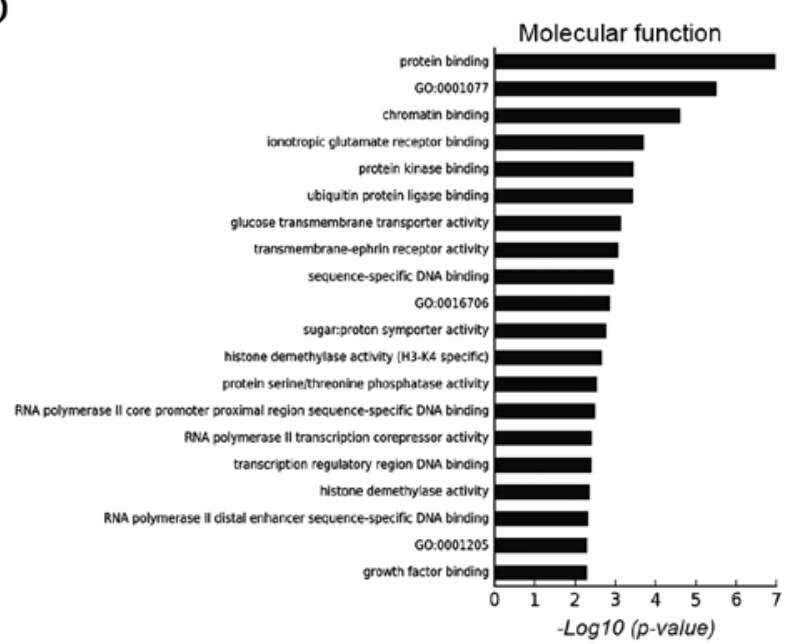

Figure 2. Enrichment analysis of pathways and GO terms for predicted target genes. (A) Pathway analysis based on the KEGG database. (B) GO analysis according to biological process. (C) GO analysis according to cellular components. (D) GO analysis according to molecular function. GO, Gene Ontology; KEGG, Kyoto Encyclopaedia of Genes and Genomes.
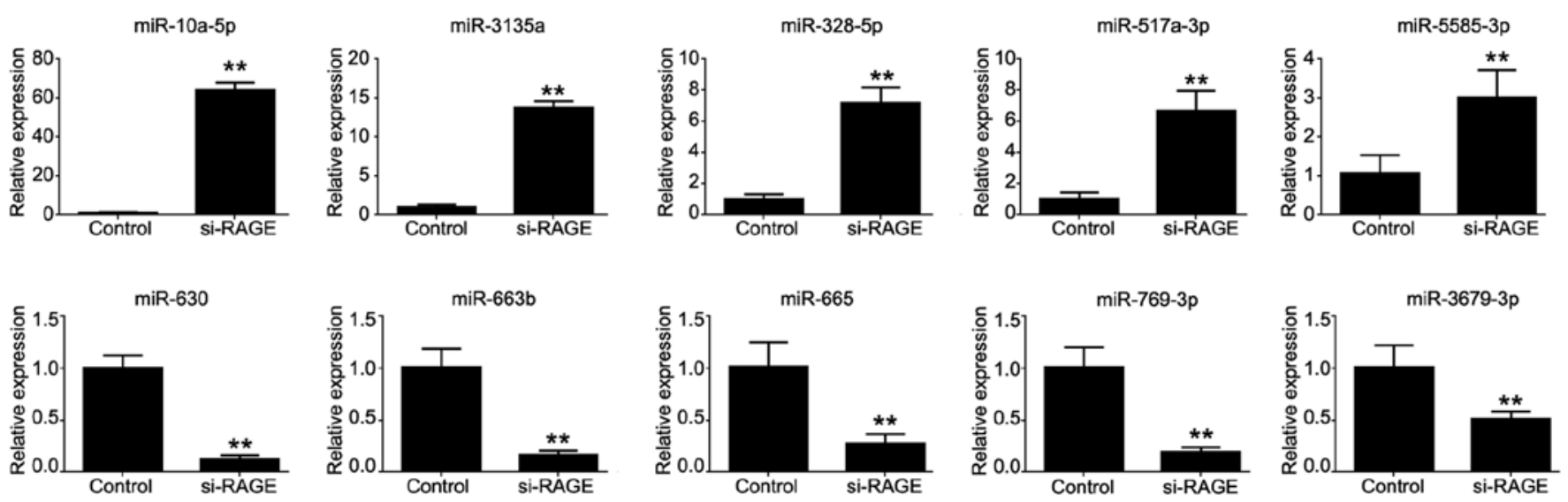

Figure 3. qPCR validation of the 10 differentially expressed miRNAs from the microarray data. $n=3,{ }^{* *} \mathrm{P}<0.01$ vs. the control group. miRNAs, microRNAs.

RAGE; hence, we analysed the relationship between RAGE and miR-328-5p. We found that the relative expression level of RAGE was markedly decreased when miR-328-5p was overexpressed in MDA-MB-231 cells (Fig. 5A and B). Then we analysed the correlation between RAGE and miR-328-5p expression in 13 samples of breast cancer tissue. We found that there was a negative correlation between RAGE and miR-328-5p expression in breast cancer tissue (Fig. 5C). 
A

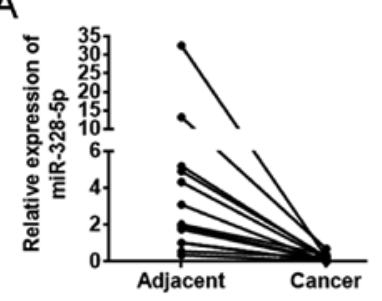

D

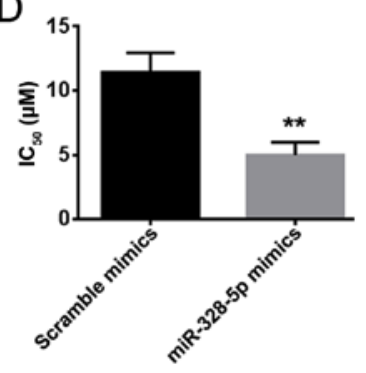

$\mathrm{B}$

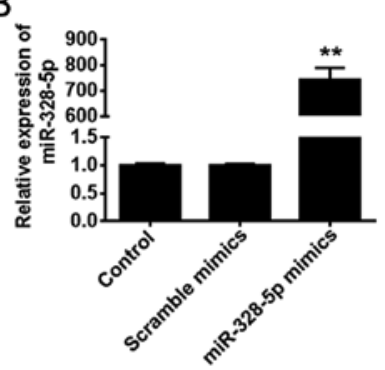

C

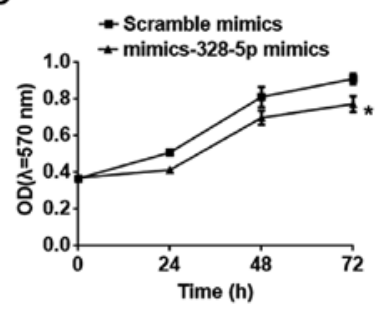

E

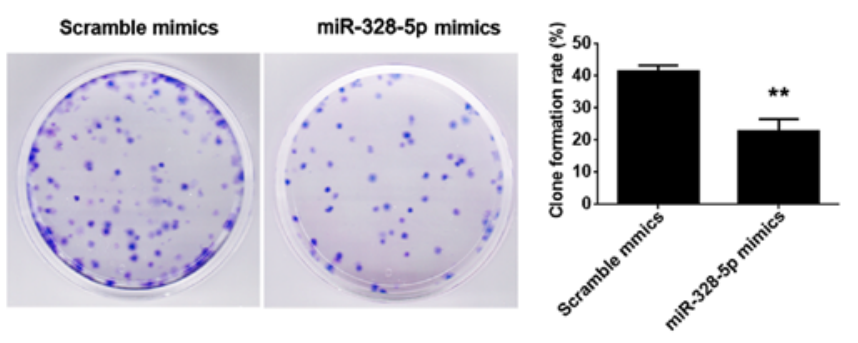

$\mathrm{F}$
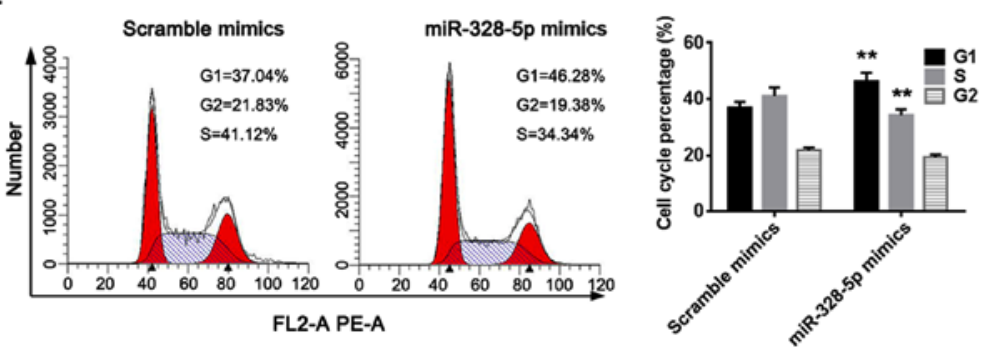

Figure 4. miR-328-5p regulates cell proliferation and the cell cycle. (A) The expression of miR-328-5p in breast cancer tissues was lower than in adjacent healthy tissues in 13 paired clinical samples. (B) The miR-328-5p overexpression cell model was established and successfully detected by qPCR. (C) miR-328-5p overexpression inhibited cell proliferation by MTT assay. (D) Chemotherapy resistance was suppressed in the miR-328-5p mimic group by MTT assay. (E) The capability of clone formation was inhibited in the miR-328-5p mimic group. (F) The cell cycle was arrested in phase G1/S in the miR-328-5p mimic group. $\mathrm{n}=3,{ }^{*} \mathrm{P}<0.05,{ }^{* *} \mathrm{P}<0.01$ vs. the scrambled mimic group.

A

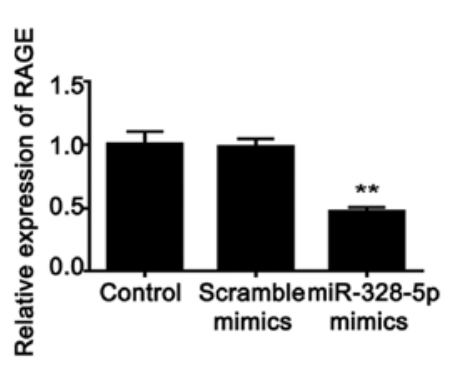

D

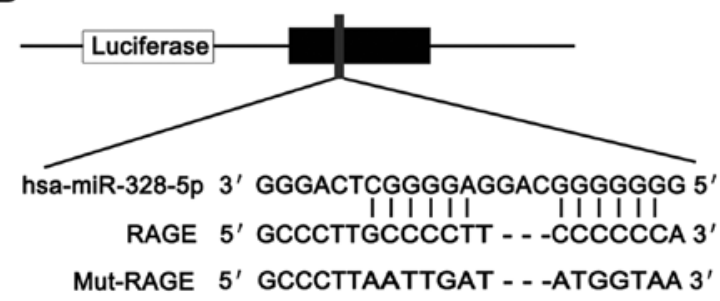

B

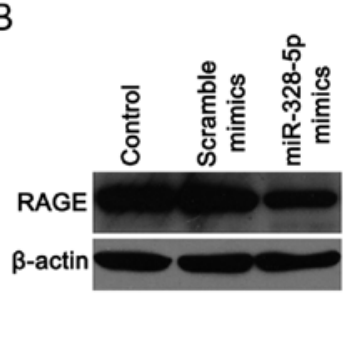

C

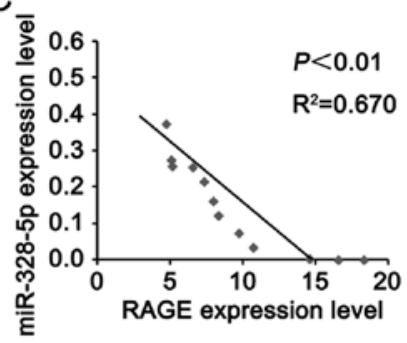

$\mathrm{E}$

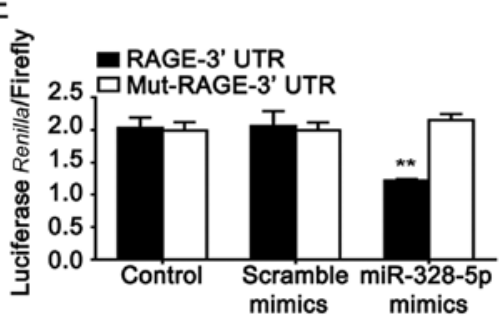

Figure 5. RAGE is a target gene of miR-328-5p. (A) The relative expression level of RAGE mRNA is decreased in miR-328-5p mimic cells analysed by qPCR. (B) The relative expression level of RAGE mRNA is decreased in miR-328-5p mimic cells analysed by western blotting. (C) The relativity rate of miR-328-5p and RAGE in 13 breast cancer tissues. (D) The predicted binding site of miR-328-5p and RAGE. (E) The relationship between RAGE and miR$328-5 \mathrm{p} 3$ was assessed by luciferase reporter assay. $n=3,{ }^{* *} \mathrm{P}<0.01$ vs. the control or mutant group. RAGE, receptor for advanced glycosylation end-product specific receptor. 
A

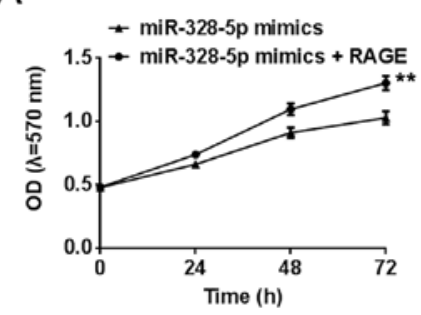

B

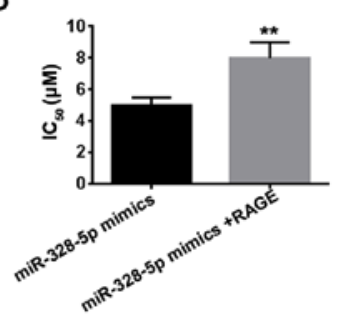

C
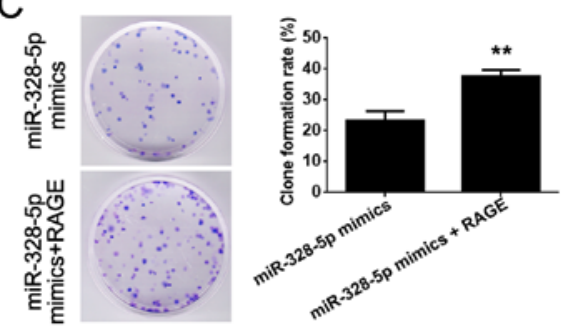

E
D

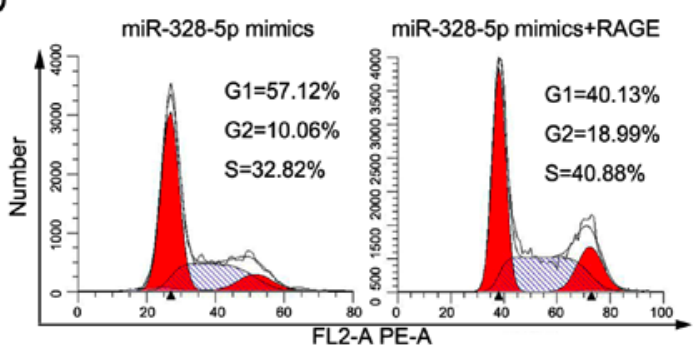

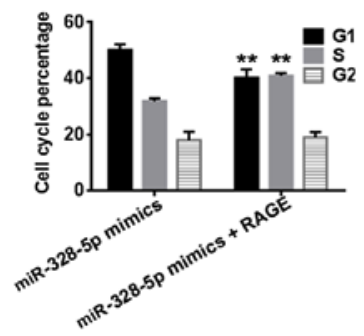

Figure 6. The effect of miR-328-5p in MDA-MB-231 cells is achieved by targeting RAGE. (A) RAGE overexpression reversed the cell growth inhibition caused by miR-328-5p mimics via MTT assay. (B) RAGE overexpression reversed the suppressed chemotherapy resistance caused by miR-328-5p mimics. (C) RAGE overexpression reversed the inhibited capability of clone formation caused by miR-328-5p mimics. (D) RAGE overexpression reversed the inhibited cell cycle caused by miR-328-5p mimics. (E) Protein levels of RAGE, NF- $\mathrm{\kappa B}$ and cyclin D1 were detected by western blotting. $n=3$, ** $\mathrm{P}<0.01$ vs. the miR-328-5p mimics group. RAGE, receptor for advanced glycosylation end-product specific receptor.

Online (http://www.targetscan.org/) bioinformatics predictions revealed that RAGE was a target of miR-328-5p. The Wt-RAGE-3'UTR or Mut-RAGE-3'UTR luciferase reporter vector was generated, respectively (Fig. 5D). We further performed a luciferase reporter assay to confirm their relationship in MDA-MB-231 cells. As shown in Fig. 5E, luciferase activity was significantly downregulated only in cells co-transfected with the miR-328-5p mimics and the Wt-RAGE-3'UTR vector, which indicated that miR-328-5p could directly bind to the 3' untranslated region (3'UTR) of RAGE in breast cancer cells.

Effect of miR-328-5p in MDA-MB-231 is achieved by targeting RAGE. After confirming that RAGE was the target of miR-328-5p, we investigated whether the function of miR328-5p in MDA-MB-231 cells was associated with RAGE by co-transfecting the overexpression vector of RAGE in cells overexpressing miR-328-5p to further observe cellular function changes. We found that RAGE overexpression could reverse the inhibition of cell growth, chemotherapy resistance, clone formation ability and cell cycle progression caused by the miR-328-5p mimics (Fig. 6A-D). We used western blotting to assess the protein expression level of RAGE, nuclear factor $\kappa$-light-chain-enhancer of activated $B$ cells (NF- $\kappa B$ ) and cyclin D1. We found that RAGE enhanced the expression levels of these proteins (Fig. 6E).

\section{Discussion}

The effects of miR-328-5p in breast cancer molecular pathogenesis were thoroughly investigated in this study. Low expression of miR-328-5p in breast cancer tissues and high expression in RAGE-interfering cells were detected. Therefore, we predicted that the expression of miR-328-5p plays an important role in breast cancer development and may be regarded as a tumour-suppressor factor. To confirm this hypothesis, a miR-328-5p overexpression model was established in MDA-MB-231 cells. After modelling, cell growth, cell proliferation, drug resistance and cell cycle patterns were inhibited in the group of miR-328-5p mimics. Moreover, we found that there was a target relationship between miR-328-5p and RAGE. Therefore, we concluded that miR-328-5p inhibits the development of breast cancer cells by targeting RAGE.

RAGE is regarded as an oncogene and is overexpressed in many types of cancers such as colon (19) and pancreatic cancer (20) and melanoma (21). In our previous research (7), we found that the RAGE expression level was much higher in MDA-MB-231 cells than in other breast cancer cells. Therefore, we chose MDA-MB-231 cells to assess the miRNA microarray in order to explore the mechanism of RAGE as the main research object in this study. MDA-MB-231 (triple-negative basal subtype) exhibits markedly high proliferation (22-24) and has more aggressive clinical behaviour, with a higher recurrence rate, than other breast cancer subtypes (25-27). Hence, it has been a great challenge to find another line of treatment for this subtype.

In the miRNA microarray KEGG analysis results, we found that interference by RAGE influences many cancerrelated pathways such as Ras, MAPK, PI3K/Akt and TGF $\beta$ signalling pathways. The differentially expressed miRNAs are also closely related with cancer, as shown in Table I.

Among the differentially expressed miRNAs, miR-328-5p suppressed the survival of oesophageal cancer cells (28), inhibited cervical cancer cell proliferation and tumorigenesis (29) and was downregulated in colorectal cancer (30). Although miR-328-5p has been reported to be associated with cancer resistance, there are few reports on breast cancer; hence, we chose miR-328-5p as our target gene. 
Notably, in the results of the cellular function experiments, we found that the cellular functions produced by the overexpression of miR-328-5p coincided with those produced by interference with RAGE, as previously indicated by our study (7). Then, the target relationship between miR-328-5p and RAGE was confirmed by software prediction and luciferase reporter assay. A previous study revealed that the function of RAGE was associated with NF- $\kappa$ B and cyclin D1. $\mathrm{NF}-\kappa \mathrm{B}$ is a protein complex that controls DNA transcription. Aberrant regulation of $\mathrm{NF}-\kappa \mathrm{B}$ has been linked to cancer and $\mathrm{NF}-\kappa \mathrm{B}$ stimulates proliferation in different cell types, including human breast cancers (31). Cyclin D1 is a protein involved in normal cell cycle regulation and is responsible for the transition from the G1 (resting) phase to the S (DNA synthesis) phase. In this study, the western blotting results in Fig. 6E suggest that miR-328-5p regulates breast cancer through these two pathways by targeting RAGE.

For our future research, we will collect more clinical samples and prognoses to analyse the value of miR-328-5p as a diagnosis marker. Moreover, we would like to demonstrate whether or not miR-328-5p plays the same role in other breast cancer cell lines or in other cancers entirely. In addition, the relationship between miR-328-5p and other signalling pathways obtained by biological analysis needs to be addressed. Concerning RAGE, there are many studies on the enhancement of invasive function; however, in our study, the function of miR-328-5p was not related with invasiveness in breast cancer cells. Furthermore, we intend to continue researching the other miRNAs from the microarray results and discover other pathways in which RAGE regulates invasion.

We conclude that miR-328-5p overexpression reduced the proliferation of breast cancer cells MDA-MB-231 by targeting RAGE. Accordingly, overexpression of miR-328-5p or interference with RAGE could be helpful in minimising breast cancer proliferation. These data revealed that $\mathrm{miR}-328-5 \mathrm{p}$ represents a novel strategy for the genetic therapeutic intervention of breast cancer.

\section{Acknowledgements}

Not applicable.

\section{Funding}

The present study was supported by a grant from the Natural Science Foundation of Hunan Province, China (no. 2017JJ3423).

\section{Availability of data and materials}

The datasets used during the present study are available from the corresponding author upon reasonable request.

\section{Authors' contributions}

TL and WW conceived and designed the study. TL, YY, QH and $\mathrm{XM}$ performed the experiments. TL and WW wrote the paper. YY, QH and XM reviewed and edited the manuscript. All authors read and approved the manuscript and agree to be account for all aspects of the research in ensuring that the accuracy or integrity of any part of the work are appropriately investigated and resolved.

\section{Ethics approval and consent to participate}

All experimental protocols were approved by the Ethical Committee of the Third Xiangya Hospital of Central South University (Changsha, China).

\section{Consent for publication}

Not applicable.

\section{Competing interests}

The authors state that they have no competing interests.

\section{References}

1. Ferlay J, Soerjomataram I, Dikshit R, Eser S, Mathers C, Rebelo M, Parkin DM, Forman D and Bray F: Cancer incidence and mortality worldwide: Sources, methods and major patterns in GLOBOCAN 2012. Int J Cancer 136: E359-E386, 2015.

2. Poellinger A: Near-infrared imaging of breast cancer using optical contrast agents. J Biophotonics 5: 815-826, 2012.

3. Onitilo AA, Engel JM, Greenlee RT and Mukesh BN: Breast cancer subtypes based on ER/PR and Her2 expression: Comparison of clinicopathologic features and survival. Clin Med Res 7: 4-13, 2009.

4. Lohrisch C and Piccart M: HER2/neu as a predictive factor in breast cancer. Clin Breast Cancer 2: 129-135, discussion 136-137, 2001.

5. Fabian MR, Sundermeier TR and Sonenberg N: Understanding how miRNAs post-transcriptionally regulate gene expression. Prog Mol Subcell Biol 50: 1-20, 2010.

6. Mitchell PS, Parkin RK, Kroh EM, Fritz BR, Wyman SK, Pogosova-Agadjanyan EL, Peterson A, Noteboom J, O'Briant KC, Allen A, et al: Circulating microRNAs as stable blood-based markers for cancer detection. Proc Natl Acad Sci USA 105: 10513-10518, 2008.

7. Radia AM, Yaser AM, Ma X, Zhang J, Yang C, Dong Q, Rong P, Ye B, Liu S and Wang W: Specific siRNA targeting receptor for advanced glycation end products (RAGE) decreases proliferation in human breast cancer cell lines. Int J Mol Sci 14: 7959-7978, 2013.

8. Stoetzer OJ, Fersching DM, Salat C, Steinkohl O, Gabka CJ, Hamann U, Braun M, Feller AM, Heinemann V, Siegele B, et al: Circulating immunogenic cell death biomarkers HMGB1 and RAGE in breast cancer patients during neoadjuvant chemotherapy. Tumour Biol 34: 81-90, 2013.

9. Khan S, Wall D, Curran C, Newell J, Kerin MJ and Dwyer RM: MicroRNA-10a is reduced in breast cancer and regulated in part through retinoic acid. BMC Cancer 15: 345, 2015.

10. Chang CH, Fan TC, Yu JC, Liao GS, Lin YC, Shih AC, Li WH and Yu AL: The prognostic significance of RUNX2 and miR-10a/10b and their inter-relationship in breast cancer. J Transl Med 12: 257, 2014.

11. Pan YZ, Morris ME and Yu AM: MicroRNA-328 negatively regulates the expression of breast cancer resistance protein (BCRP/ABCG2) in human cancer cells. Mol Pharmacol 75: 1374-1379, 2009.

12. Yoshitomi T, Kawakami K, Enokida H, Chiyomaru T, Kagara I, Tatarano S, Yoshino H, Arimura H, Nishiyama K, Seki N, et al: Restoration of miR-517a expression induces cell apoptosis in bladder cancer cell lines. Oncol Rep 25: 1661-1668, 2011.

13. Liu RF, Xu X, Huang J, Fei QL, Chen F, Li YD and Han ZG: Down-regulation of miR-517a and miR-517c promotes proliferation of hepatocellular carcinoma cells via targeting Pyk2. Cancer Lett 329: 164-173, 2013.

14. Zhou CX, Wang CL, Yu AL, Wang QY, Zhan MN, Tang J, Gong XF, Yin QQ, He M, He JR, et al: MiR-630 suppresses breast cancer progression by targeting metadherin. Oncotarget 7: 1288-1299, 2016. 
15. Hu H, Li S, Cui X, Lv X, Jiao Y, Yu F, Yao H, Song E, Chen Y, Wang M, et al: The overexpression of hypomethylated miR-663 induces chemotherapy resistance in human breast cancer cells by targeting heparin sulfate proteoglycan 2 (HSPG2). J Biol Chem 288: 10973-10985, 2013.

16. Luo EC, Chang YC, Sher YP, Huang WY, Chuang LL, Chiu YC, Tsai MH, Chuang EY and Lai LC: MicroRNA-769-3p downregulates $N D R G 1$ and enhances apoptosis in MCF-7 cells during reoxygenation. Sci Rep 4: 5908, 2014.

17. Qiu HJ, Lu XH, Yang SS, Weng CY, Zhang EK and Chen FC: MiR-769 promoted cell proliferation in human melanoma by suppressing GSK3B expression. Biomed Pharmacother 82: 117, 2016.

18. Pu Q, Huang Y, Lu Y, Peng Y, Zhang J, Feng G, Wang C, Liu L and Dai Y: Tissue-specific and plasma microRNA profiles could be promising biomarkers of histological classification and TNM stage in non-small cell lung cancer. Thorac Cancer 7: 348-354, 2016.

19. Fuentes MK, Nigavekar SS, Arumugam T, Logsdon CD, Schmidt AM, Park JC and Huang EH: RAGE activation by S100P in colon cancer stimulates growth, migration, and cell signaling pathways. Dis Colon Rectum 50: 1230-1240, 2007.

20. Takada M, Koizumi T, Toyama H, Suzuki Y and Kuroda Y: Differential expression of RAGE in human pancreatic carcinoma cells. Hepatogastroenterology 48: 1577-1578, 2001.

21. Wagner NB, Weide B, Reith M, Tarnanidis K, Kehrel C, Lichtenberger R, Pflugfelder A, Herpel E, Eubel J, Ikenberg K, et al: Diminished levels of the soluble form of RAGE are related to poor survival in malignant melanoma. Int J Cancer 137 2607-2617, 2015 .

22. Lerma E, Peiro G, Ramón T, Fernandez S, Martinez D, Pons C, Muñoz F, Sabate JM, Alonso C, Ojeda B, et al: Immunohistochemical heterogeneity of breast carcinomas negative for estrogen receptors, progesterone receptors and Her2/neu (basal-like breast carcinomas). Mod Pathol 20: 1200-1207, 2007.
23. Subhawong AP, Subhawong T, Nassar H, Kouprina N, Begum S, Vang R, Westra WH and Argani P: Most basal-like breast carcinomas demonstrate the same $\mathrm{Rb}-/ \mathrm{p} 16+$ immunophenotype as the HPV-related poorly differentiated squamous cell carcinomas which they resemble morphologically. Am J Surg Pathol 33: 163-175, 2009.

24. Reis-Filho JS and Tutt ANJ: Triple negative tumours: A critical review. Histopathology 52: 108-118, 2008.

25. Nielsen TO, Hsu FD, Jensen K, Cheang M, Karaca G, Hu Z, Hernandez-Boussard T, Livasy C, Cowan D, Dressler L, et al: Immunohistochemical and clinical characterization of the basal-like subtype of invasive breast carcinoma. Clin Cancer Res 10: 5367-5374, 2004.

26. Abd El-Rehim DM, Pinder SE, Paish CE, Bell J, Blamey RW, Robertson JF, Nicholson RI and Ellis IO: Expression of luminal and basal cytokeratins in human breast carcinoma. J Pathol 203: 661-671, 2004.

27. Fan C, Oh DS, Wessels L, Weigelt B, Nuyten DS, Nobel AB, van't Veer LJ and Perou CM: Concordance among geneexpression-based predictors for breast cancer. N Engl J Med 355: 560-569, 2006

28. Han N, Zhao W, Zhang Z and Zheng P: MiR-328 suppresses the survival of esophageal cancer cells by targeting PLCE1. Biochem Biophys Res Commun 470: 175-180, 2016.

29. Wang X and Xia Y: microRNA-328 inhibits cervical cancer cell proliferation and tumorigenesis by targeting TCF7L2. Biochem Biophys Res Commun 475: 169-175, 2016.

30. Xu XT, Xu Q, Tong JL, Zhu MM, Nie F, Chen X, Xiao SD and Ran ZH: MicroRNA expression profiling identifies miR-328 regulates cancer stem cell-like SP cells in colorectal cancer. Br J Cancer 106: 1320-1330, 2012.

31. Jones RL, Rojo F, A'Hern R, Villena N, Salter J, Corominas JM, Servitja S, Smith IE, Rovira A, Reis-Filho JS, et al: Nuclear $\mathrm{NF}-\kappa \mathrm{B} / \mathrm{p} 65$ expression and response to neoadjuvant chemotherapy in breast cancer. J Clin Pathol 64: 130-135, 2011. 